\title{
Economia Solidária e Saúde Mental: Problemáticas e estratégias para a inclusão social de pessoas em sofrimento mental
}

Solidarity Economy and Mental Health: Issues and strategies for the social inclusion of people in mental suffering

Economía Solidaria y Salud Mental: Temas y estrategias para la inclusión social de personas en sufrimiento mental

Recebido: 07/06/2021 | Revisado: 16/06/2021 | Aceito: 17/06/2021 | Publicado: 25/06/2021

\author{
Caique Lima Sette Franzoloso \\ ORCID: https://orcid.org/0000-0001-7272-791X \\ Universidade Federal do Paraná, Brasil \\ E-mail: caiquefranzoloso@gmail.com \\ Luís Felipe Ferro \\ ORCID: https://orcid.org/0000-0001-8935-104X \\ Universidade Federal do Paraná, Brasil \\ E-mail: luisfelipeferro@gmail.com
}

\begin{abstract}
Resumo
Em contexto brasileiro, o movimento da Reforma Psiquiátrica propôs o desmonte do modelo manicomial e a instauração de um novo paradigma de atenção à saúde mental, baseado no tratamento comunitário em liberdade e em propostas de inclusão social. A atual política nacional de Saúde Mental, conhecida como Rede de Atenção Psicossocial (RAPS), assume como um de seus objetivos a promoção e apoio aos usuários de seus serviços em sua (re)inserção laboral. Paralelamente, a Economia Solidária se apresenta como um modo de organização material da vida e das relações de trabalho pautado na primazia pelo respeito ao ser humano em sua relação entre si e com o meio ambiente e nos ideais de cooperação, autogestão e solidariedade. Em confluência, diferentes iniciativas de geração de trabalho e renda baseadas na Economia Solidária vêm sendo estruturadas por diferentes pontos de atenção da RAPS, possibilitando novas formas de inclusão social. Nesse cenário, a pesquisa em tela se trata de uma revisão sistemática de abordagem qualitativa, cujo objetivo é apresentar as potencialidades, desafios e estratégias adotadas abordadas pela literatura para fortalecer a interface entre os campos da Saúde Mental e Economia Solidária. Os resultados sugerem: a importância da assunção, pelas iniciativas, de seu compromisso na garantia do direito ao trabalho; as oficinas assistidas como principal estratégia de formação de empreendimentos; a falta de respaldo jurídico e de políticas públicas para constituição das iniciativas; além da falta de espaços adequados à comercialização e o baixo retorno financeiro aos empreendimentos.
\end{abstract}

Palavras-chave: Economia solidária; Saúde mental; Inclusão social.

\begin{abstract}
The Psychiatric Reform movement in Brazil proposed the dismantling of the asylum model and the establishment of a new paradigm of mental health care, based on community treatment done in freedom and on proposals for social inclusion. The current national policy on Mental Health, known as the Psychosocial Care Network (RAPS), aims to promote and support its service's users in their (re)insertion into work. In parallel, the Solidarity Economy presents itself as a means of material organization of life and work relationships based on the primacy of respect for human beings in their relationship with each other and with the environment, as well as on the ideals of cooperation, selfmanagement and solidarity. At the same time, different initiatives to generate work and income based on the Solidarity Economy have been structured by different RAPS attention points, enabling new forms of social inclusion. In this scenario, the research in question consists of a systematic review with a qualitative approach, whose objective is to present the potentialities, challenges and strategies adopted in the literature to strengthen the interface between the fields of Mental Health and Solidarity Economy. The results suggest: the importance of the initiatives' commitment to guarantee the right to work; the assisted workshops as the main strategy for the formation of enterprises; the lack of legal and public policy support for the constitution of the initiatives; as well as the lack of adequate spaces for commercialization and the low financial return to the enterprises.
\end{abstract}

Keywords: Solidarity economy; Mental health; Social inclusion. 


\begin{abstract}
Resumen
En Brasil, el movimiento de la Reforma Psiquiátrica propuso la extinción del modelo de asilo u hospicio de tipo manicomio, estableciendo un nuevo paradigma de atención en salud mental, basado en el tratamiento comunitario en libertad y en propuestas de inclusión social. La actual política nacional de Salud Mental, conocida como Red de Atención Psicosocial (RAPS), asume entre sus objetivos la promoción y apoyo a los ciudadanos para su (re) inserción laboral. Asimismo, la Economía Solidaria representa una forma de organización material de las relaciones de vida y trabajo basada en la primacía del respeto al ser humano en su relación entre sí y con el medio ambiente y en ideales de cooperación, autogestión y solidaridad. Al mismo tiempo, distintas iniciativas de creación de empleos e ingresos basadas en la Economía Solidaria se han estructurado mediante diferentes puntos de atención del RAPS, permitiendo nuevas formas de inclusión social. En ese contexto, esta investigación se trata de una revisión sistemática con enfoque cualitativo, cuyo objetivo es presentar las potencialidades, desafíos y estrategias presentadas en la literatura para fortalecer la interface entre los campos de la Salud Mental y la Economía Solidaria. Los resultados sugieren: la importancia de que las iniciativas asuman su compromiso de garantizar el derecho al trabajo; los talleres asistidos como principal estrategia para la formación de empresas; poco soporte legal y de políticas públicas para la constitución de las iniciativas; además de la falta de espacios adecuados para la comercialización y la baja rentabilidad de las empresas.
\end{abstract}

Palabras clave: Economía solidaria; Salud mental; Inclusión social.

\title{
1. Introdução
}

Em contexto brasileiro, o movimento da Reforma Psiquiátrica, promovido por diferentes atores sociais desde o final da década de 1970, buscou repensar o modelo manicomial de atenção e a situação de exclusão e violação de direitos que pessoas em sofrimento mental vinham vivenciando (Amarante \& Nunes, 2018; Pitta, 2016). A partir deste processo, a assistência à Saúde Mental vem passando por grandes transformações, procurando construir melhores condições de tratamento e inovadoras maneiras de proporcionar cuidado comunitário (Alves, 2016).

Nesse contexto, a Lei 10.216/2001 e a Portaria n 3088/2011 são alguns dos marcos legais da Reforma Psiquiátrica no país. Enquanto a primeira estabelece o necessário redirecionamento da assistência em saúde mental, configurando seus esforços para a construção do cuidado comunitário, a segunda regulamenta a atual Política Nacional de Saúde Mental, conhecida como Rede de Atenção Psicossocial (RAPS), procurando operacionalizar um modelo de atenção de base territorial (Brasil, 2001, 2011). Dessa maneira, os pontos de atenção previstos pela RAPS devem atuar sob a lógica interdisciplinar e se organizar em rede, procurando ofertar cuidado integral e aliar indissociavelmente intervenção clínica a propostas de inclusão social (Brasil, 2011, 2017a).

Dentre seus nove objetivos específicos, previstos em seu artigo terceiro, a RAPS sustenta a necessidade da elaboração de estratégias que proporcionem a inclusão social de seu público alvo por meio do trabalho.

IV - promover a reabilitação e a reinserção das pessoas com transtorno mental e com necessidades decorrentes do uso de crack, álcool e outras drogas na sociedade, por meio do acesso ao trabalho, renda e moradia solidária (Brasil, 2011).

A Economia Solidária (ECOSOL), por sua vez, propõe uma configuração social do trabalho pautada em princípios cooperativos, autogestionários e solidários, valorizando o ser humano e suas relações entre si e com o meio ambiente (Bueno, 2012; Cayres, 2012; Rodrigues \& Pinho, 2012). A ECOSOL, desta forma, toma o ser humano como elemento central da atividade produtiva e econômica, em detrimento à competição, acumulação excessiva de capital e de riquezas privadas (Alcântara, 2003a; Gadotti, 2009; Singer, 2002, 2005). Estruturalmente, a ECOSOL se organiza...

...quando pessoas se associam para construir empreendimentos solidários, produtivos, redes de trocas, instituições financeiras, escolas, entidades representativas etc., que apontam para uma sociedade marcada pela solidariedade (Singer, 2005, p. 11). 
Como campo de confluência, diferentes iniciativas de inclusão pelo trabalho pautadas na Economia Solidária vêm sendo desenvolvidas por pontos de atenção próprios à RAPS. Neste contexto, uma importante parceria foi estabelecida em 2005 entre o Ministério da Saúde e o Ministério do Trabalho e Emprego, por meio da Secretaria Nacional de Economia Solidária (SENAES) (Brasil, 2005). Assim, materializou-se formalmente o compromisso entre os Ministérios para a promoção de ações e políticas públicas voltadas à inclusão social de pessoas em sofrimento mental pelo trabalho. Embora diferentes estratégias tenham sido desenvolvidas e projetos fomentados em vários pontos do Brasil, no ano de 2018 a SENAES foi rebaixada ao status de subsecretaria e, em 2019, foi transformada em um departamento da Secretaria de Inclusão Social e Produtiva Urbana, atualmente vinculado ao Ministério da Cidadania.

Contudo, mesmo com a proliferação das experiências, ainda existem muitos desafios a serem superados para proporcionar suporte às iniciativas, à geração de renda e à inclusão social de pessoas em sofrimento mental (Martins et al., 2017; Pinho et al., 2014; Rimoli \& Cayres, 2012).

Diante do exposto, o presente artigo procura analisar a literatura científica produzida pela interface entre Saúde Mental e Economia Solidária, apresentando suas barreiras e potencialidades, assim como estratégias desenvolvidas para fortalecer empreendimentos solidários e, com eles, a geração de trabalho e renda para pessoas em sofrimento mental.

\section{Método}

Para alcançar seus objetivos, o presente estudo foi estruturado por meio de uma revisão integrativa. A revisão integrativa é um procedimento metodológico que, de maneira planejada e sistemática, possibilita a síntese e análise do conhecimento científico já produzido sobre um determinado tema, além de permitir sua reprodução metodológica por outros pesquisadores (Castro, 2006).

Enquanto passos metodológicos, foram realizadas as seguintes etapas, conforme recomendam Botelho, Cunha e Macedo (2011): identificação do tema e seleção da questão de pesquisa; estabelecimento de critérios de inclusão e exclusão; identificação dos estudos pré-selecionados e selecionados; categorização dos estudos selecionados; análise e interpretação dos resultados; apresentação da revisão.

Dessa forma, foram utilizados os descritores "Economia Solidária" e "Saúde Mental" no portal da Biblioteca Virtual em Saúde (BVS). Os critérios de inclusão adotados foram: artigos científicos que versem sobre a interface entre Saúde Mental e Economia Solidária; artigos em português, com resumo e texto completos disponíveis na BVS; e artigos publicados entre 2010 e 2020.

A partir da primeira busca com os descritores foram obtidos 59 resultados. Após aplicados os filtros, reduziram-se para 41. Procedeu-se com a exclusão dos materiais duplicados, leitura dos títulos e resumos e enquadre aos temas da Saúde Mental e da Economia Solidária. Ao final, 19 resultados foram selecionados para a leitura integral, etapa em que um artigo foi excluído por não abordar a interface pretendida, conforme ilustrado na Figura 1. 
Figura 1 - Seleção dos resultados.

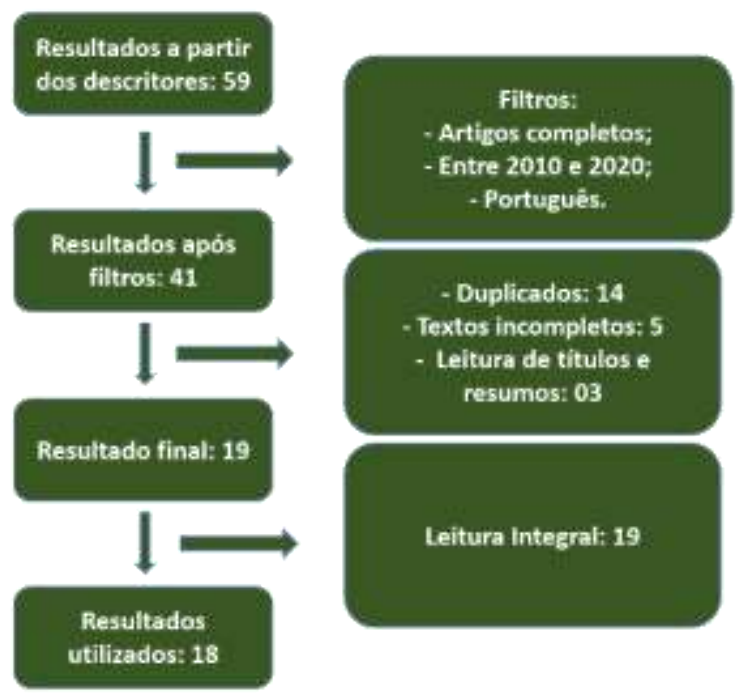

Fonte: Os autores.

Trata-se de uma pesquisa de abordagem qualitativa que, segundo Minayo e Guerreiro (2014), é o tipo de investigação que valoriza os processos, suas compreensões e retira o foco exclusivamente dos resultados. A análise dos dados dos artigos selecionados foi realizada com o auxílio da matriz de síntese. Segundo Botelho, Cunha e Macedo (2011), a matriz de síntese é um instrumento voltado a organizar e categorizar os dados da bibliografia analisada, prevenindo possíveis erros de análise por parte do pesquisador. Enquanto estrutura, utilizou-se a seguinte matriz de síntese.

Quadro 1: Matriz de Síntese construída para fins desta pesquisa.

\begin{tabular}{|l|l|l|l|l|l|l|l|l|}
\hline Referência & Ano & Estado & Revista & $\begin{array}{l}\text { Tipo de } \\
\text { Estudo }\end{array}$ & $\begin{array}{l}\text { Núcleo de } \\
\text { sentido 1 }\end{array}$ & $\begin{array}{l}\text { Núcleo de } \\
\text { sentido 2 }\end{array}$ & $\begin{array}{l}\text { Núcleo de } \\
\text { sentido 3 }\end{array}$ & $\begin{array}{l}\text { Núcleo de } \\
\text { sentido ... } \mathbf{x}\end{array}$ \\
\hline Artigo 1 & & & & & & & & \\
\hline Artigo 2 & & & & & & & & \\
\hline Artigo 3 & & & & & & & & \\
\hline Artigo ... x & & & & & & & & \\
\hline
\end{tabular}

Fonte: Os autores.

A partir da elaboração das categorias, advindas da análise dos materiais bibliográficos, foram utilizadas literaturas e legislações que pudessem dar respaldo às reflexões, procurando aprofundar questionamentos e proporcionar maior contribuição ao campo. Dessa forma, foram elaboraras quatro categorias, a serem apresentadas a seguir.

\section{Resultados e Discussão}

Observou-se que todos os artigos possuem metodologia de abordagem qualitativa, com predominância de periódicos especializados em Terapia Ocupacional, Psicologia, Enfermagem e um periódico interdisciplinar (T.O 7; Psicologia 6; enfermagem 4; saúde e sociedade 1). A maioria dos artigos (89\%) foi publicada entre os anos de 2011 e 2015 e se distribuem em periódicos de todo país, apesar da grande centralidade na região sudeste (78\%), especialmente no estado de São Paulo, o qual conta $66 \%$ das publicações.

Moraes e Castro-Silva (2016) concentraram seus esforços na análise dos empreendimentos solidários brasileiros, encontrando, em seu trabalho, maior predominância de experiências na Região Sudeste, o que corrobora com os dados 
bibliográficos encontrados nesta pesquisa. Ainda, Santiago e Yasui (2015), ao analisarem dados advindos do Cadastro de Iniciativas de Inclusão Social pelo Trabalho (CIST), plataforma criada para mapear nacionalmente tais iniciativas, apontam:

Dados do CIST dão uma dimensão das ações articuladoras entre trabalho e atenção em saúde mental no território. Informações de 2011 apontam a existência, no Brasil, de 640 iniciativas de geração de trabalho e renda na saúde mental. Os estados com os maiores números de iniciativas são Rio de Janeiro (114 iniciativas) e São Paulo (99) (Santiago \& Yasui, 2015, p. 705).

Quanto aos artigos aqui levantados, a tabela abaixo apresenta sua localização temporal e as principais revistas que colaboram para o aprofundamento no tema.

Tabela 1: apresentação dos estudos selecionados elencados conforme ano de publicação.

\begin{tabular}{|c|c|c|c|c|}
\hline Autores & Título & Ano & Revista & $\begin{array}{l}\text { Estado do } \\
\text { periódico }\end{array}$ \\
\hline $\begin{array}{l}\text { (Lussi \& Pereira, } \\
\text { 2011) }\end{array}$ & $\begin{array}{l}\text { Empresa social e economia solidária: } \\
\text { perspectivas no campo da inserção laboral } \\
\text { de portadores de transtorno mental }\end{array}$ & 2011 & $\begin{array}{l}\text { Revista da Escola de } \\
\text { Enfermagem da } \\
\text { USP }\end{array}$ & SP \\
\hline (Filizola et al., 2011) & $\begin{array}{l}\text { Saúde mental e economia solidária: a } \\
\text { família na inclusão pelo trabalho }\end{array}$ & 2011 & $\begin{array}{l}\text { Revista da Escola de } \\
\text { Enfermagem da } \\
\text { USP }\end{array}$ & SP \\
\hline $\begin{array}{l}\text { (Andrade \& Da } \\
\text { Costa-Rosa, 2011) }\end{array}$ & $\begin{array}{l}\text { Dispositivo intercessor - uma perspectiva } \\
\text { multirreferencial de produção de } \\
\text { conhecimento }\end{array}$ & 2011 & $\begin{array}{l}\text { Revista de } \\
\text { Psicologia da } \\
\text { UNESP }\end{array}$ & SP \\
\hline (Pedroza et al., 2012) & $\begin{array}{l}\text { Articulação saúde mental e economia } \\
\text { solidária: relato de projeto de inclusão } \\
\text { social }\end{array}$ & 2012 & $\begin{array}{l}\text { Revista da rede de } \\
\text { enfermagem do } \\
\text { nordeste }\end{array}$ & $\mathrm{CE}$ \\
\hline $\begin{array}{l}\text { (Lussi \& Morato, } \\
\text { 2012) }\end{array}$ & $\begin{array}{l}\text { O significado do trabalho para usuários de } \\
\text { serviços de saúde mental inseridos em } \\
\text { projetos de geração de renda vinculados ou } \\
\text { não ao movimento da economia solidária }\end{array}$ & 2012 & $\begin{array}{l}\text { Cadernos de Terapia } \\
\text { Ocupacional da } \\
\text { UFSCar }\end{array}$ & SP \\
\hline $\begin{array}{l}\text { (Lussi \& Shiramizo, } \\
\text { 2013) }\end{array}$ & $\begin{array}{l}\text { Oficina integrada de geração de trabalho e } \\
\text { renda: estratégia para formação de } \\
\text { empreendimento econômico solidário }\end{array}$ & 2013 & $\begin{array}{l}\text { Revista de Terapia } \\
\text { Ocupacional da } \\
\text { Universidade de São } \\
\text { Paulo }\end{array}$ & SP \\
\hline $\begin{array}{l}\text { (Bonadio \& Silveira, } \\
\text { 2013) }\end{array}$ & $\begin{array}{l}\text { Economia solidária e reabilitação } \\
\text { vocacional no campo da drogadição: } \\
\text { Possibilidades e limites das práticas atuais }\end{array}$ & 2013 & Saude e Sociedade & SP \\
\hline (Lima et al., 2013) & $\begin{array}{l}\text { Políticas Públicas De Saúde Mental E } \\
\text { Economia Solidária: Construção De Uma } \\
\text { Nova Concepção }\end{array}$ & 2013 & $\begin{array}{l}\text { Revista enfermagem } \\
\text { UFPE on line }\end{array}$ & $\mathrm{PE}$ \\
\hline (Andrade et al., 2013) & $\begin{array}{l}\text { Loucura e trabalho no encontro entre saúde } \\
\text { mental e economia solidária }\end{array}$ & 2013 & $\begin{array}{l}\text { Psicologia: Ciência } \\
\text { e Profissão }\end{array}$ & DF \\
\hline (Barreto et al., 2013) & $\begin{array}{l}\text { A economia solidária na inclusão social de } \\
\text { usuários de álcool e outras drogas: } \\
\text { reflexões a partir da análise de } \\
\text { experiências em Minas Gerais e São Paulo }\end{array}$ & 2013 & $\begin{array}{l}\text { Cadernos de } \\
\text { Psicologia Social do } \\
\text { Trabalho }\end{array}$ & SP \\
\hline $\begin{array}{l}\text { (Andrade \& Da } \\
\text { Costa-Rosa, 2014) }\end{array}$ & $\begin{array}{l}\text { O encontro da loucura com o trabalho: } \\
\text { concepções e práticas no transcurso da } \\
\text { história }\end{array}$ & 2014 & $\begin{array}{l}\text { Revista } \\
\text { Interinstitucional de } \\
\text { Psicologia }\end{array}$ & MG \\
\hline (Kinker, 2014) & $\begin{array}{l}\text { Enfrentamentos e construção de projetos } \\
\text { de trabalho para a superação da } \\
\text { laborterapia }\end{array}$ & 2014 & $\begin{array}{l}\text { Cadernos de Terapia } \\
\text { Ocupacional da } \\
\text { UFSCar }\end{array}$ & SP \\
\hline (Ferro et al., 2015) & $\begin{array}{l}\text { Economia Solidária, Saúde Mental e a } \\
\text { prática do terapeuta ocupacional: relatos de } \\
\text { participantes de um grupo de geração de } \\
\text { trabalho e renda }\end{array}$ & 2015 & $\begin{array}{l}\text { Cadernos de Terapia } \\
\text { Ocupacional da } \\
\text { UFSCar }\end{array}$ & SP \\
\hline
\end{tabular}




\begin{tabular}{|c|c|c|c|c|}
\hline $\begin{array}{l}\text { (Santiago \& Yasui, } \\
\text { 2015) }\end{array}$ & $\begin{array}{l}\text { Saúde Mental E Economia Solidária: } \\
\text { Cartografias Do Seu Discurso Político }\end{array}$ & 2015 & $\begin{array}{l}\text { Psicologia \& } \\
\text { Sociedade }\end{array}$ & MG \\
\hline (Campos et al., 2015) & $\begin{array}{l}\text { Saúde Mental E Economia Solidária: a } \\
\text { Experiência De Usuários E Trabalhadores } \\
\text { De Um Caps II }\end{array}$ & 2015 & $\begin{array}{l}\text { Cadernos de Terapia } \\
\text { Ocupacional da } \\
\text { UFSCar }\end{array}$ & SP \\
\hline $\begin{array}{l}\text { Morato \& Lussi, } \\
\text { 2015) }\end{array}$ & $\begin{array}{l}\text { Iniciativas de geração de trabalho e renda, } \\
\text { economia solidária e terapia ocupacional: } \\
\text { aproximações possíveis e construções } \\
\text { necessárias }\end{array}$ & 2015 & $\begin{array}{l}\text { Cadernos de Terapia } \\
\text { Ocupacional da } \\
\text { UFSCar }\end{array}$ & SP \\
\hline $\begin{array}{l}\text { (Moraes \& Castro- } \\
\text { Silva, 2016) }\end{array}$ & $\begin{array}{l}\text { Sentidos e Processos Psicossociais } \\
\text { envolvidos na Inclusão pelo Trabalho na } \\
\text { Saúde Mental }\end{array}$ & 2016 & $\begin{array}{l}\text { Psicologia: Ciência } \\
\text { e Profissão }\end{array}$ & DF \\
\hline $\begin{array}{l}\text { (Silva \& Ferigato, } \\
\text { 2017) }\end{array}$ & $\begin{array}{l}\text { Saúde Mental E Trabalho: Diálogos Sobre } \\
\text { Direito, Desejo E Necessidade De Acesso }\end{array}$ & 2017 & $\begin{array}{l}\text { Cadernos } \\
\text { Brasileiros de } \\
\text { Terapia } \\
\text { Ocupacional }\end{array}$ & SP \\
\hline
\end{tabular}

Fonte: Os autores.

\subsection{Geração de trabalho e renda na saúde mental: entre trabalho e terapia}

Grande parte dos trabalhos levantados ressaltam a importância de iniciativas de geração de trabalho e renda que possibilitem a inclusão social de pessoas em sofrimento mental no trabalho, garantindo a ampliação de sua contratualidade e circulação social, a geração de trabalho e renda e a construção de projetos de vida (Andrade et al., 2013; Andrade \& Da CostaRosa, 2014; Barreto et al., 2013; Bonadio \& Silveira, 2013; Kinker, 2014; Lima et al., 2013; Moraes \& Castro-Silva, 2016; Morato \& Lussi, 2015; Pedroza et al., 2012; Silva \& Ferigato, 2017).

A atual política nacional de Saúde Mental, como vimos acima, é sensível a tal demanda, prevendo enquanto um de seus objetivos específicos a promoção de ações que garantam o acesso ao trabalho. A RAPS, ainda, é mais específica ao afirmar, como um de seus componentes as "Estratégias de Reabilitação Psicossocial", estruturadas como "iniciativas de trabalho e geração de renda, empreendimentos solidários e cooperativas sociais" (Brasil, 2017b).

Mesmo tendo este pano de fundo para as iniciativas que se situam na interface entre Economia Solidária e Saúde Mental, diferentes autores relatam dissidências entre suas finalidades. Para Morato e Lussi (2015), a problemática ocorre na medida em que as experiências muitas vezes caminham sobre a linha tênue da dicotomia entre o "viés terapêutico" de suas práticas e a garantia do direito ao trabalho. As autoras, ao tratarem sobre as iniciativas de geração de trabalho e renda na Saúde Mental, afirmam:

...as atribuições dadas ao trabalho ainda são ambíguas tanto entre os usuários quanto entre os serviços de saúde mental, posto que, por vezes, é tido como um dispositivo terapêutico, e, por outras, como única maneira de os sujeitos conquistarem e exercerem sua cidadania (Morato \& Lussi, 2015, p. 743).

Dentre os autores que discutem tal problemática, foi unânime o posicionamento de que a garantia do direito ao trabalho deve ser o foco principal das iniciativas (Andrade Et Al., 2013; Andrade \& Da Costa-Rosa, 2014; Kinker, 2014; Morato \& Lussi, 2015; Bonadio \& Silveira, 2013; Santiago \& Yasui, 2015; Silva, 2017; Ferro; Cardoso \& Loureiro, 2015; Ferigato, 2017). Os estudos de Kinker (2014) e de Santiago e Yasui (2015), reforçam, ainda, a importância de marcar os espaços de produção como destinados ao trabalho, foco dado à inclusão social, de maneira a superar a abordagem terapêutica tradicional.

No tocante a garantia de direito ao trabalho, Morato e Lussi (2015) demonstram a importância existente na interface da Saúde Mental com a Economia Solidária: 
A união entre economia solidária e saúde mental tem suscitado importantes problematizações acerca do direito das pessoas com transtorno mental quanto a compartilharem os espaços e as decisões sobre suas produções, a forma como produzem e o destino que dão a essa produção, mas, sobretudo, quanto à questão da autonomia e do direito ao trabalho (Morato \& Lussi, 2015, p.741).

Ferro, Cardoso e Loureiro (2015) colaboram com a reflexão ao apresentar diferentes nuances práticas do trabalho do terapeuta ocupacional no suporte às iniciativas situadas na interface entre Saúde Mental e Economia Solidária. Em sua argumentação, os autores explicitam a necessidade de que tais ações tenham como foco a garantia do direito ao trabalho, guia que orienta a prática profissional em vários aspectos pragmáticos do cotidiano produtivo da iniciativa. Desta forma, passam a se tornar primordiais: a organização de processos e postos de trabalho; o recrutamento de pessoas em sofrimento mental com determinadas experiências profissionais e/ou projetos de vida que se relacionem diretamente à iniciativa produtiva; o fortalecimento da produção e da comercialização; o desenvolvimento de ações formativas dos trabalhadores com foco na produção, comercialização e gestão do empreendimento; etc.

Ao terapeuta e ao próprio grupo caberia, nesse contexto, a clareza quanto à situação do grupo como espaço vinculado ao trabalho. Faz-se premente a necessidade de pensar e organizar postos de trabalho e que o "seletivo" não seja exclusivamente pautado em questões diagnósticas, encaminhamentos pautados na doença e/ou possibilidade de convivência em um grupo, mas sim que respondam às demandas próprias ao grupo no tocante à sua produção (Ferro; Cardoso \& Loureiro, 2015, p. 108).

Tratar-se-ia neste contexto, então, de repensar a prática profissional, desterritorializando modelos e intervenções pautados na clínica tradicional para compreender a importância de investir, junto com o usuário (agora trabalhador), na estruturação de projetos de vida que garantam a ampliação de sua rede, da contratualidade e da circulação sociais, e possibilitem seu exercício profissional e a geração de renda. Neste sentido, em entrevistas realizadas com terapeutas ocupacionais que desenvolvem experiências voltadas à geração de trabalho e renda com base na Economia Solidária para pessoas em sofrimento mental em diferentes municípios de São Paulo, Morato e Lussi (2015) apontam a importância da atuação de profissionais sob a ótica do modelo da Reabilitação Psicossocial.

Retomando alguns apontamentos do modelo da Reabilitação Psicossocial, conforme proposto por Saraceno (2001), Campos et al. (2015) relatam se tratar de...

...conjunto de estratégias direcionadas a aumentar as possibilidades de trocas, valorizando o sujeito e seu contexto, a reabilitação psicossocial propõe uma abordagem focada na contratualidade dos usuários, o que implica a necessidade ética de contemplar três vértices da vida de qualquer cidadão: casa, trabalho e lazer (Campos et al., 2015, p. 412).

O modelo da Reabilitação Psicossocial, conforme proposto por Saraceno (2001), ao afirmar como uma das pedras fundamentais da Saúde Mental a investidura na garantia do trabalho, possibilitaria a dissolução da dicotomia, apontada pelos autores estudados, entre "viés terapêutico" e as práticas tangentes à Economia Solidária em sua interface Saúde Mental (Ferro; Cardoso \& Loureiro, 2015; Kinker, 2014; Lussi \& Morato, 2012; Santiago \& Yasui, 2015). Para o autor, ao assumir vertiginosamente, como trabalho da Saúde Mental, a necessidade da criação conjunta e parceira de possibilidades concretas de inclusão pelo trabalho, a clínica se tornaria indissociável do processo da construção de vivências produtivas, afirmando o papel e a importância do agente da saúde no apoio às situações de sofrimento reais, fenomenicamente ancoradas, procurando a todo instante ampliar a contratualidade social, a circulação comunitária e as possibilidades de vida dos usuários, agora trabalhadores (Saraceno, 2001). 
Desta forma, a dicotômica apontada poderia encontrar síntese ao se ampliar o olhar sobre as questões relacionadas ao trabalho e à Saúde Mental e seus determinantes, o que possibilitaria versar sobre uma outra clínica, conforme sublinha Silva e Ferigato (2017):

É transversal (...) o borramento das fronteiras entre o trabalho e o tratamento no caso das pessoas com transtornos mentais vivendo experiências de geração de renda em espaços geridos pelo setor saúde e conduzidos por profissionais clínicos. Não se desejou, com isso, negar a clínica, mas considerá-la em seu sentido mais amplo. A clínica ampliada deve sempre compor com os temas da vida, no sentido de que considerar a vida aprimora o seu olhar para o ato de criar vida quando se investe no cuidado da saúde, mas não deve capturar a vida, porque uma necessidade de se ter um trabalho digno, satisfatório do ponto de vista das dimensões trabalhadas e de outras mais segue sendo uma necessidade que quem reclama é a própria vida (Silva \& Ferigato, 2017, p.815).

Outro dos pontos destacados por diferentes autores a respeito das iniciativas de geração de trabalho e renda pautadas na Economia Solidária (Barreto et al., 2013; Filizola et al., 2011; Lussi \& Pereira, 2011), diz respeito à sua potencialidade para ampliação da autonomia do público-alvo dos serviços de Saúde Mental. Neste sentido, a Economia Solidária, haja vista sua fundamentação sobre os princípios da autogestão, cooperação e solidariedade, configura potentes dispositivos, por meio de seus empreendimentos, para possibilitar a construção da autonomia.

Outro aspecto importante relacionado à proposta da economia solidária é a questão da autonomia. Ela se relaciona estreitamente com o entendimento de que a organização também se configura, conforme explicitado anteriormente, como um espaço de expressão política. Isso porque uma característica fundamental do movimento é a vivência de uma gestão democrática, em que todos os participantes podem influenciar diretamente nas decisões da organização. As decisões coletivas, bem como a possibilidade de experienciar uma posição de igualdade dentro da organização, pode ser um fator capaz de despertar maior interesse dos participantes (Barreto; Lopes \& Paula, 2013, p.53).

Morato e Lussi (2015) apresentam, em sua análise dos relatos de profissionais entrevistados, a potência atribuída às iniciativas de geração de trabalho e renda para a promoção da autonomia dos usuários. Nesse caso, a autonomia a que se referem as autoras remonta o conceito de Kinoshita (2001, citado por Morato \& Lussi, 2015), por estar alinhado aos pressupostos da reabilitação psicossocial.

Portanto, para o autor, a autonomia diz respeito à capacidade de um sujeito produzir normas e ordens em sua vida a partir das variadas situações que enfrente, de forma que reabilitar, sob esta perspectiva, representa um processo de reconstrução do poder contratual do sujeito com vistas a aumentar sua autonomia (Morato \& Lussi, 2015, p741).

Moraes e Castro-Silva (2016), ao discutir a questão da autonomia, aponta que a maioria dos empreendimentos solidários, como será apresentado adiante, surge dentro dos equipamentos da saúde, em especial dos Centros de Atenção Psicossocial (CAPS). Kinker (2014) defende que a autonomia pode ser melhor garantida se os espaços destinados ao trabalho estiverem preferencialmente funcionando fora dos equipamentos de saúde. No entanto, enfatiza que o desvinculamento dos serviços não dispensa a presença de um profissional que acompanhe o grupo (Kinker, 2014).

Tal demanda até mesmo se encontra materializada no Relatório Final da IV Conferência Nacional de Saúde Mental Intersetorial, o qual apresenta como uma de suas propostas para guiar as ações e políticas públicas:

Regulamentar, na Política Nacional de Saúde Mental, a implantação e consolidação dos projetos e oficinas de geração de trabalho e renda, priorizando a sua realização em sedes próprias, fora dos Centros de Atenção Psicossocial (CAPS), reafirmando que o espaço destinado ao acolhimento de pessoas com transtornos mentais e particularmente à crise (Centro de Atenção Psicossocial) deve ser distinto do espaço de trabalho (Brasil, 2010a, p. 114). 


\subsection{Estratégias para o fortalecimento de empreendimentos econômicos solidários na saúde mental}

A partir do leme apontado à garantia do direito ao trabalho, que proveja condições concretas de subsistência humana e, concomitantemente, participação social e o estabelecimento de relações comunitárias, torna-se relevante compreender a configuração dos empreendimentos solidários e as estratégias relatadas pela literatura para dar suporte às iniciativas.

Kinker (2014) expõe que os objetivos que conduziram à implementação das iniciativas influenciam diretamente na condução das atividades, na postura adotada pelos profissionais que os acompanham e no movimento de permanecer ou não dependente do serviço. No presente estudo, foi possível observar que doze artigos apresentam relatos que afirmam a oficina como principal estratégia para a formação dos grupos e os serviços de saúde mental como locais mais utilizados (Andrade et al., 2013; Barreto et al., 2013; Bonadio \& Silveira, 2013; Campos et al., 2015; Filizola et al., 2011; Kinker, 2014; Lima et al., 2013; Lussi \& Morato, 2012; Lussi \& Shiramizo, 2013; Moraes \& Castro-Silva, 2016; Morato \& Lussi, 2015; Pedroza et al., 2012).

Segundo Moraes e Castro-Silva (2016, p.750), “...apesar de estarem instaladas em todo o Brasil, a predominância destas atividades é na Região Sudeste, sua organização mais comum é por meio de oficinas e os locais mais utilizados são os próprios Centros de Atenção Psicossocial (CAPS)”.

Para Lussi e Shiramizo (2013), as oficinas inseridas na interface entre Saúde Mental e Economia Solidária se apresentam como um espaço capaz de gerar oportunidades e fornecer ferramentas que favoreçam a inclusão social pelo trabalho dos usuários. Para as autoras, podem ser utilizadas para “...possibilitar a formação dos participantes em economia solidária e criar condições para que os participantes se organizassem de forma coletiva, com vistas a formar um empreendimento econômico solidário" (Lussi \& Shiramizo, 2013, p.30).

A frequência e as condições sistemáticas em que as oficinas ocorrem são fatores que podem determinar maior ou menor probabilidade de adesão dos participantes (Lussi \& Shiramizo, 2013).

Após constituídos, alguns empreendimentos recebem ainda um suporte técnico por meio da incubação. A incubação se caracteriza como um processo de qualificação do empreendimento econômico solidário para todas as etapas da produção, comercialização, gestão, organização do processo de trabalho e formação dos recursos humanos. Esse processo é desenvolvido e executado, em sua maioria, por Incubadoras Tecnológicas de Cooperativas Populares (ITCPs) (Filizola et al., 2011; Lussi \& Shiramizo, 2013; Pedroza et al., 2012).

As ITCPs assumem relevante papel no suporte e na qualificação dos empreendimentos econômicos solidários. Nesse contexto, é de vital importância o compromisso do Estado com programas e políticas públicas que apoiem e fomentem a estruturação e proliferação das ITCPs (Andrade \& Da Costa-Rosa, 2014; Pedroza et al., 2012). Como exemplos, Andrade e Da Costa-Rosa (2014) citam o:

(...) Programa Nacional de Incubadoras de Cooperativas Populares (PRONINC); a criação da Portaria No 1.169/MS em 2005, que destina incentivo financeiro para municípios que desenvolvam projetos de Inclusão Social pelo Trabalho (sua terceira chamada foi em 2012), destinados a pessoas portadoras de transtornos mentais e/ou de transtornos decorrentes do uso de álcool e outras drogas; cursos de gestão de empreendimentos de saúde mental e ECOSOL para trabalhadores da área; dentre outras ações. Entretanto, ainda há muito que fazer nesse campo (Andrade \& Da Costa-Rosa, 2014, P.36).

No contexto da parceria entre o Ministério da Saúde e o até então Ministério do Trabalho e Emprego (Brasil, 2005), emergiram também importantes programas de incentivo à Economia Solidária, por meio da qualificação de pessoas e instituições para Incubação, conforme apontam Santiago e Yasui (2015):

(...) em conformidade com as diretrizes das propostas de articulações entre Ministério da Saúde e MTE, ao longo do ano de 2008 ocorreram Ciclos de Cursos de Capacitação em Incubação de Empreendimentos Solidários da Saúde 
Mental objetivando a instrumentalização de usuários, familiares e trabalhadores da saúde mental (Santiago \& Yasui, 2015, p. 705).

Para além, Ferro, Cardoso e Loureiro (2015) sublinham a importância da formação e manutenção de Redes de Economia Solidária (Ferro; Cardoso \& Loureiro, 2015). As redes são formadas por múltiplos atores sociais, empreendimentos solidários e instituições, voltados a congregar forças e promover ações que fortaleçam a Economia Solidária, possibilitando a qualificação dos empreendimentos, ampliação das possibilidades de comércio, a integração de arranjos produtivos, a reivindicação de ações e políticas públicas, ampliação da captação de recursos, etc.

Proporcionando subsídios para maior aprofundamento no tema, conforme previsto na metodologia deste trabalho, cabe citar os artigos de Ferro, Burnagui e Pinto (2018), o qual apresenta estratégias para a formação e manutenção de Redes de Economia Solidária, e de Ferro, Franzoloso e Burnagui (2020), voltado a amadurecer formas de captação de recursos que podem ser potencializadas a partir da configuração de Redes de Economia Solidária.

Diferentes legislações municipais e estaduais que regulamentam Políticas Públicas de Economia Solidária, ainda, ressaltam a importância da formação e manutenção de redes de Economia Solidária. Em nossa realidade locorregional, a lei municipal 14.786/2016, que regulamenta Política Municipal de fomento à Economia Popular Solidária de Curitiba, prevê em seu art. $2^{\circ}$ :

Parágrafo único. É prioridade da economia popular solidária a formação de redes de colaboração que integrem grupos de consumidores, produtores e prestadores de serviços para a prática do mercado solidário (Curitiba, 2016).

Destacando, ainda, como um de seus objetivos:

XIX - fomentar a criação da rede local e metropolitana de economia popular solidária (Curitiba, 2016).

A Rede de Saúde Mental e Economia Solidária de Curitiba e Região Metropolitana (LIBERSOL), ainda, compila legislações de variados municípios, estados e Federação, os quais podem proporcionar subsídios normativos para fortalecer os empreendimentos solidários e o trabalho no campo da Saúde Mental (libersol.org).

Reitera-se, desta forma, a importância e a necessidade de políticas públicas que possam garantir o apoio e fomento às iniciativas situadas na interface entre Saúde Mental e Economia Solidária, as quais podem normatizar o papel do poder executivo no oferecimento de ações que garantam aos empreendimentos solidários, além do apoio para a constituição de redes: qualificações; linhas de crédito subsidiadas; apoio a ações de pesquisa que venham a fortalecer os empreendimentos; concessão de espaços e equipamentos públicos para produção e comercialização; dentre outras ações necessárias ao desenvolvimento dos empreendimentos solidários (Lima; Silva \& Cruz, 2013; Curitiba, 2016; Paraná, 2018).

\subsection{Desafios para a constituição jurídica dos empreendimentos}

Na medida em que os empreendimentos solidários passam por processos de incubação e/ou avançam em seus estágios de maturação, espera-se que estejam cada vez mais aptos a desenvolver sua produção e comercialização de maneira cada vez mais autônoma. Um dos avanços mais esperados é que os empreendimentos econômicos solidários possam se formalizar enquanto pessoas jurídicas (Moraes \& Castro-Silva, 2016; Santiago \& Yasui, 2015). Tal formalização possibilita a emissão de nota fiscal, acesso a linhas de crédito com melhores taxas, o encaminhamento de projetos a editais de financiamento que sejam específicos a empreendimentos formalizados, a participação em processos de licitação, entre outros benefícios restritos à pessoa jurídica.

A partir da análise dos artigos levantados pelo presente trabalho, constatou-se que, dentre os formatos jurídicos assumidos pelos grupos de geração de renda, os principais encontrados foram: os grupos informais; associações; e as 
cooperativas (Alcântara, 2003b; Goerck \& Damascena, 2009; Pinho et al., 2014; Singer, 2002). No âmbito desta pesquisa, 14 artigos mencionam a configuração de empreendimentos solidários como grupos informais, cinco como associações e apenas um como cooperativa.

Os empreendimentos informais, embora possibilitem a organização coletiva dos trabalhadores para o exercício de suas atividades produtivas, pautadas nos princípios propostos pela Economia Solidária de autogestão e cooperação (Singer, 2002), apresentam diferentes limitações. Apesar de muitos dos empreendimentos informais possuírem um nome que represente o coletivo, normas e/ou estatutos/regimentos que regem a participação de seus membros, não existe uma figura jurídica que lhe é associada, ou seja, um CNPJ. Na condição de informalidade, o empreendimento se torna frágil e mais suscetível às adversidades do mercado, tornando-o, portanto, mais vulnerável a um processo de desarticulação (Silva \& Ferigato, 2017).

Uma grande problemática apontada, e que acusa a falta de baliza legal/normativa brasileira para fomentar a inclusão social pelo trabalho, diz respeito aos benefícios sociais e previdenciários. Estruturalmente, ao optar pela formalização do empreendimento solidário como cooperativa, o estado brasileiro compreende a situação finalizada de preparação do usuário para o exercício laborativo, comprometendo os benefícios que, por ventura, perceba.

Tal situação impõe quadro problemático aos profissionais e usuários envolvidos com grupos de geração de trabalho e renda em sua busca por estruturar a iniciativa como cooperativa de trabalho - e a proposta quanto à sua implantação, lançada ao usuário, ao qual cabe a opção benefício X cooperativa, apresenta qualidade praticamente única: recusável (Ferro; Cardoso \& Loureiro, 2015, p.111).

Ora, como optar, neste contexto, por abrir mão de quaisquer benefícios, se a opção junto aos empreendimentos solidários, muitos deles bastante frágeis, não consegue garantir aos seus participantes condições mínimas de subsistência e manutenção da vida?

Assim, os empreendimentos se veem obrigados a buscar uma figura jurídica que seja apropriada ao modo de organização solidário do grupo e que, simultaneamente, supra suas demandas formais. Nesse sentido, dentre a bibliografia levantada pela pesquisa, o formato de pessoa jurídica mais utilizado foi a associação. Com base em literaturas complementares, entende-se que, apesar de não ser uma figura jurídica apropriada para dar suporte a empreendimentos voltados a gerar trabalho e renda, a associação oferece menos empecilhos burocráticos, com custos reduzidos, possibilitando a congregação dos participantes do empreendimento em uma figura jurídica (Alcântara, 2003a; Heckert, 2003).

Nesta pesquisa, foram identificados relatos de cinco associações: Associação pró saúde mental trabalharte em Juiz de Fora/MG; Suricato em Belo Horizonte/MG; NOT Associação Cornélia Vlieg em Campinas/SP; a ATUT, associação de usuários e pessoas da comunidade do entorno do Hospital São Pedro em Porto Alegre/RS; e Associação Arnaldo Gilberti em Curitiba/PR (Andrade et al., 2013; Andrade \& Da Costa-Rosa, 2014; Bonadio \& Silveira, 2013; Ferro et al., 2015; Lussi \& Shiramizo, 2013; Morato \& Lussi, 2015; Santiago \& Yasui, 2015; Silva \& Ferigato, 2017).

Santiago e Yasui (2015), por sua vez, ressaltam que a melhor figura jurídica para empreendimentos econômicos solidários seria a cooperativa, haja vista sua finalidade econômica. Neste estudo, contudo, foi identificada apenas uma experiência que se estruturou como cooperativa: a Cooperativa de Reciclagem em Santos (Moraes \& Castro-Silva, 2016).

Silva e Ferigato (2017) contribuem com as reflexões, apontando que...

...apesar dos esforços do Programa Nacional de Apoio ao Associativismo e Cooperativismo Social, o cooperativismo social não dispõe de um marco legal que permita seu pleno desenvolvimento. A atual lei reguladora $\mathrm{n}^{\circ} 9.867 / 99$ possui restrições que não permitem a formalização das iniciativas solidárias, que tendem a incorrer na informalidade ou na precariedade institucional (Silva \& Ferigato, 2017, p. 804). 
A enunciada lei, embora destine esforços para criar e dispor sobre o funcionamento das Cooperativas Sociais, somente conceitua este dispositivo, delegando sua função de proporcionar estrutura para a inclusão social pelo trabalho das seguintes populações:

Art. 3 Consideram-se pessoas em desvantagem, para os efeitos desta Lei:

I - os deficientes físicos e sensoriais;

II - os deficientes psíquicos e mentais, as pessoas dependentes de acompanhamento psiquiátrico permanente, e os egressos de hospitais psiquiátricos;

III - os dependentes químicos;

IV - os egressos de prisões;

(...)

VI - os condenados a penas alternativas à detenção;

VII - os adolescentes em idade adequada ao trabalho e situação familiar difícil do ponto de vista econômico, social ou afetivo (Brasil, 1999).

A legislação, contudo, não regulamenta quaisquer funcionamentos das cooperativas sociais que possibilitem sua concreta edificação. A incipiência da normatização das cooperativas sociais é ampla e, em seu breve corpo textual: não baliza o apoio público e não sistematiza ou facilita qualquer procedimento burocrático para a abertura, manutenção e/ou consolidação das cooperativas sociais; não normatiza a percepção de benefícios pelos trabalhadores descritos; e não descreve em pormenores qualquer funcionamento que provesse guarida aos empreendimentos solidários.

Nesse sentido, diversas são as críticas tecidas por diferentes autores acerca da legislação brasileira de cooperativismo social (Brasil, 1999), que, em sua forma limitada, é incapaz de regulamentar satisfatoriamente o funcionamento desta forma de cooperativa ou, sequer, quaisquer estímulos necessários à sua implementação (Andrade et al., 2013; Ferro et al., 2015; Lima et al., 2013; Lussi \& Pereira, 2011; Santiago \& Yasui, 2015; Silva \& Ferigato, 2017).

Neste panorama, variados movimentos podem ser destacados na tentativa de fornecer maior suporte e fomento para que empreendimentos possam se formalizar enquanto cooperativas sociais (Andrade et al., 2013; Andrade \& Da Costa-Rosa, 2014; Lima et al, 2013; Moraes \& Castro-Silva, 2016; Santiago \& Yasui, 2015). A IV Conferência Nacional de Saúde Mental (Brasil, 2010a) discutiu a manutenção do benefício continuado aos usuários cooperados e aprovou, enquanto proposta para guiar as políticas públicas no campo, a necessidade de:

838. Garantir a modificação da legislação para que os beneficiários do INSS com sofrimento psíquico possam desenvolver alguma atividade laboral que complemente sua renda, considerando-se as diretrizes da economia solidária, sem prejuízo do recebimento integral do seu benefício (Brasil, 2010a, p. 135-136).

683. Garantir o Benefício de Prestação Continuada (BPC) aos usuários dos serviços de Saúde Mental, mesmo estando inseridos em cooperativas sociais.

684. Garantir a Seguridade Social aos participantes do cooperativismo social e mecanismos de incentivos com redução de impostos. (Brasil, 2010a, p. 115).

193. Garantir a Economia Solidária como política pública nas três esferas de governo através: do reconhecimento e apoio aos projetos de incubação e trabalho que ocorrem nos equipamentos públicos de Saúde Mental; da regulação da lei de cooperativas sociais; da implantação de ações estratégicas para fomentar as cadeias produtivas solidárias; da capacitação dos empreendimentos de economia solidária para todas as etapas do processo produtivo; favorecer, por meio de incentivos, as cadeias produtivas solidárias e a disputa de mercado de consumo solidário; incentivar ponto de comércio justo e solidário (Brasil, 2010a, p. 47).

Por sua vez, a pauta tomou lugar na II Conferência Nacional de Economia Solidária, realizada em 2010, a qual aprovou como proposta:

46. [...] c) garantir também que os benefícios de seguridade e proteção social dos integrantes das cooperativas sociais sejam preservados, pelo menos até que os ganhos do trabalho cooperativo sejam suficientes, em valor e regularidade 
que garanta o bem viver, para permitir sua dispensa, sendo a fiscalização realizada pelos respectivos conselhos municipais e estaduais.

47. [...]permissão para que as pessoas em desvantagem possam ser cooperativados, assegurando a manutenção do benefício no teto de até cinco salários-mínimos enquanto permanência na cooperativa social, o que requer a criação de um programa especial da previdência social para esses trabalhadores [...] (Brasil, 2010b, p. 24-25).

Atualmente, a discussão nacional toma lugar na câmara federal, por meio do projeto de lei de $\mathrm{n}^{\circ}$ 598/2021, colocado em pauta pelo deputado Alexandre Padilha (Brasil, 2021).

\subsection{Retorno financeiro e espaços de comercialização: a realidade dos empreendimentos}

Uma das preocupações mais latentes quando se trata de ECOSOL, não apenas no âmbito da Saúde Mental, diz respeito à garantia de condições dignas, que garantam a produção e reprodução da vida humana, em base igualitária e com preocupação comunitária. Apesar de algumas experiências exitosas serem encontradas na literatura, o retorno financeiro ainda é incipiente, fazendo dessa questão um desafio, tanto para a constituição de políticas públicas, quanto para a práxis cotidiana junto aos empreendimentos (Ferro; Cardoso; Loureiro, 2015; Moraes; Castro-Silva (2016).

Apesar de oito artigos mencionarem a problemática da questão financeira (Andrade et al., 2013; Barreto et al., 2013; Ferro et al., 2015; Filizola et al., 2011; Kinker, 2014; Lussi \& Morato, 2012; Moraes \& Castro-Silva, 2016; Pedroza et al., 2012), apenas um relata uma experiência com remuneração próxima a um salário mínimo, própria à Cooperativa de Reciclagem de Santos, cuja retirada por trabalhador é de cerca de R \$700,00 por mês (Moraes \& Castro-Silva, 2016).

A partir das entrevistas e das observações participantes, verificamos que os projetos das oficinas de geração de renda geravam apenas o valor dos produtos vendidos; o da cantina e das praças, um ganho de aproximadamente $\mathrm{R} \$ 300,00$ por mês; e o de reciclagem de lixo, curiosamente cobiçado pelos seus participantes, em torno de R $\$ 700,00$ mensais (Moraes \& Castro-Silva, 2016, p. 755).

A baixa remuneração é amplamente discutida por Ferro, Cardoso e Loureiro (2015), que relatam a experiência de um grupo de geração de renda voltado à produção de bolsas de banners. Em entrevista com os usuários da Associação Arnaldo Gilberti, os autores mencionam diversas falas que retratam essa realidade, demonstrando a insatisfação dos participantes com os retornos obtidos (Ferro; Cardoso \& Loureiro, 2015). A questão financeira é ainda mais preocupante ao saber que grande parte dos grupos não chega obter remuneração acima de cem reais:

A partir dos princípios da economia solidária foram identificadas algumas características compartilhadas pelas cooperativas sociais mapeadas pelo SIES 2005-2007. Esses empreendimentos são em sua maioria organizações informais e possuem uma articulação considerável com movimentos de luta por direitos de cidadania, quando formalizados são registrados como associações. [...] Quase a totalidade desses empreendimentos produz artefatos artesanais. Na maioria dessas cooperativas, os trabalhadores são remunerados por produto ou produtividade, com remuneração inferior a R \$ 100,00 (Martins, 2009 citado Ferro; Cardoso \& Loureiro, 2015, p. 162-163).

De acordo com as experiências encontradas nesta pesquisa, os trabalhadores dos empreendimentos solidários obtêm suas receitas com base na natureza das atividades e em acordos firmados dentro do próprio grupo. Na maioria dos relatos, a remuneração está ligada à produtividade, número de horas trabalhadas ou com base na quantidade de produtos vendidos (Barreto et al., 2013; Campos et al., 2015; Ferro et al., 2015; Filizola et al., 2011; Lussi \& Shiramizo, 2013; Morato \& Lussi, 2015; Pedroza et al., 2012). No que tange à comercialização, Filizola et. al. (2011) afirmam que em sua maioria...

... ocorre em pontos fixos (na própria universidade e na cidade) e em feiras da comunidade. O valor obtido nas vendas é dividido mensalmente entre os usuários, conforme o total de horas trabalhadas (Filizola et al., 2011, p. 420). 
Dentre os estudos desta pesquisa foram identificados cinco locais de comercialização, a saber: vendas em feiras de Economia Solidária; vendas em universidades, cujo vínculo se estabelece por meio de projetos de extensão ou pelas ITCPs; venda direta ao consumidor aos arredores dos serviços; venda em pontos fixos; e venda para rede de consumidores.

A realização de feiras de economia solidária foi a estratégia mais frequente encontrada na bibliografia para a comercialização de produtos e serviços dos empreendimentos (Andrade et al., 2013; Ferro et al., 2015; Filizola et al., 2011; Moraes \& Castro-Silva, 2016). Ferro, Cardoso e Loureiro (2015) apontam ainda a importância de centros de comercialização voltados à Economia Solidária para garantir escoamento de produtos e serviços (Ferro et al., 2015; Filizola et al., 2011).

Nesse sentido, possibilitando maior aprofundamento sobre a temática, ressalta-se a importância dos Centros Públicos de Economia Solidária para proporcionar fortalecimento dos empreendimentos solidários e ampliação de possibilidades de comercialização. Segundo Goerck e Damascena (2009), os Centros Públicos de Economia Solidária se caracterizam como...

...espaços multifuncionais, que alojam um conjunto de atividades principalmente de comercialização, de formação e de articulação local da Economia Popular Solidária, que podem estar relacionadas a instituições governamentais ou não governamentais (Goerck \& Damascena, 2009, P 112).

A guarida proporcionada pelos Centros Públicos de Economia Solidária garante aos empreendimentos, para além de apoio na formação, produção, articulação e comercialização, a isenção de taxas monetárias, como o aluguel, água e luz, o que lhes confere maior possibilidade de ampliação da receita. Variadas leis que regulamentam as políticas de fomento à Economia Solidária, atribuem ao ente federativo a competência quanto à criação de Centros Públicos de Economia Solidária, inclusive prevendo apoio permanente à comercialização e concessão de espaços físicos aos empreendimentos solidários (São José dos Pinhais, 2010; Libersol.org).

Neste panorama, sublinha-se aqui a importância da mobilização popular que garanta a aprovação de leis locorregionais que regulamentem políticas públicas de Economia Solidária, o que, ao ser executada, possibilita respaldo e apoio aos empreendimentos solidários, à geração de trabalho e renda e, com isso, à inclusão social (Lima et al., 2013).

\section{Considerações finais}

A presente pesquisa buscou, por meio de uma revisão sistemática de literatura, analisar as produções científicas situadas na interface entre Saúde Mental e Economia Solidária. Destaca-se nesse contexto a relevância de periódicos da área da Psicologia e Terapia Ocupacional, bem como a totalidade dos estudos adotarem como método a abordagem qualitativa.

No contexto da Saúde Mental, identifica-se a necessidade dos espaços de geração de trabalho e renda sedimentarem suas propostas sobre o objetivo de garantir o direito ao trabalho, assumindo vertiginosamente o compromisso, já normatizado pela RAPS, de promover inclusão social pelo trabalho. Para além, é necessário superar a dicotomia entre "terapia" e "trabalho", de maneira a estruturar práticas profissionais dos agentes da saúde sob a égide de modelos que integrem de maneira indissociável ações terapêuticas a possibilidades concretas de inclusão social, garantindo apoio aos usuários de seus serviços na construção de projetos terapêuticos singulares que ampliem a contratualidade, a autonomia e a participação social. Faz-se imprescindível, desta forma, expandir a lógica do trabalho terapêutico, descolando-o de sua vertente mais clínica e reducionista, para assumir, conforme prevê a Reabilitação Psicossocial, a indissociabilidade entre processo terapêutico, trabalho e inclusão social, de maneira a garantir apoio e cuidado comunitário na estruturação de projetos de vida.

Ficaram evidenciadas, ainda, a dificuldade e a falta de suporte aos empreendimentos. Nesse sentido, foram nítidas na presente pesquisa a fragilidade da legislação brasileira, que não fornece a base jurídica adequada às demandas que os empreendimentos solidários, ainda mais os que incluem pessoas em sofrimento mental, apresentam. Por fim, foi identificada a 
carência, e assumida a importância, de políticas públicas que promovam a formação, produção, comercialização, assim como a constituição de redes de economia solidária que possibilitem apoio aos diferentes empreendimentos.

Recomenda-se que futuros trabalhos possam elucidar estratégias utilizadas por empreendimentos e/ou redes solidárias para superação dos desafios apontados por esta revisão, a fim de que tais experiências possam servir de respaldo para aqueles que ainda estão mais fragilizados. Ressalta-se, ainda, a importância de maiores publicações acerca das políticas públicas que assistam os empreendedores em sofrimento psíquico, bem como as forças que atuam em seus respectivos territórios para elaboração de estratégias para cobrança de ações do poder público.

\section{Referências}

Alcântara, F. H. C. (2003a). Institucionalismo, racionalidade e solidariedade em cooperativas populares. In Cooperativismo popular: reflexões e perspectiva (pp. 15-58). Ed. UFJF.

Alcântara, F. H. C. (2003b). Redes de Economia Solidária: estrutura do modelo organizacional e sua relação com as instituições sociais. In Cooperativismo popular: reflexões e perspectiva (pp. 177-198). Ed. UFJF.

Alves, D. S. N. (2016). Por um programa brasileiro de apoio a desospitalização. In Reabilitação psicossocial no Brasil (4th ed., pp. 37-41). Hucitec.

Amarante, P., \& Nunes, M. de O. (2018). Psychiatric reform in the SUS and the struggle for a society without asylums. Ciencia e Saude Coletiva, 23(6), 20672074. https://doi.org/10.1590/1413-81232018236.07082018

Andrade, M. C., Burali, M. A. de M., Vida, A., Fransozio, M. B. B., \& Santos, R. Z. dos. (2013). Loucura e trabalho no encontro entre Saúde Mental e Economia Solidária. Psicologia: Ciência e Profissão, 33(1), 174-191. https://doi.org/10.1590/s1414-98932013000100014

Andrade, M. C., \& Da Costa-Rosa, A. (2011). Dispositivo intercessor - uma perspectiva multirreferencial de produção de conhecimento. Revista de Psicologia Da UNESP, 10(1), 171-183. http://seer.assis.unesp.br/index.php/psicologia/article/download/575/533

Andrade, M. C., \& Da Costa-Rosa, A. (2014). O encontro da loucura com o trabalho: concepções e práticas no transcurso da história. Revista Interinstitucional de Psicologia, 7(1), 27-41.

Barreto, R. D. O., Lopes, F. T., \& Paula, A. P. P. de. (2013). A Economia Solidária na inclusão social de usuários de álcool e outras drogas: reflexões a partir da análise de experiências em Minas Gerais e São Paulo. Cadernos de Psicologia Social Do Trabalho, 16(1), 41. https://doi.org/10.11606/issn.19810490.v16i1p41-56

Bonadio, A. N., \& Silveira, C. (2013). Economia Solidária e reabilitação vocacional no campo da drogadição: possibilidades e limites das práticas atuais. Saude e Sociedade, 22(1), 99-108. https://doi.org/10.1590/S0104-12902013000100010

Botelho, L. L. R., Cunha, C. C. de A., \& Macedo, M. (2011). O método da revisão integrativa nos estudos organizacionais. Gestão e Sociedade, 5(11), 121. https://doi.org/10.21171/ges.v5i11.1220

Bueno, R. G. (2012). Reflexões sobre Saúde Mental e Economia Solidária. In Saúde Mental e Economia Solidária - armazém das oficinas: um olhar para além da produção (pp. 190-196). Medita.

Campos, I. de O., Magalhães, Y. B., Kikuchi, P., Jabur, P. de A. C., Rebouças, F., \& Pinheiro, G. M. (2015). Saúde Mental e Economia Solidária: a experiência de usuários e trabalhadores de um Caps II. Cadernos de Terapia Ocupacional Da UFSCar, 23(2), 411-415. https://doi.org/10.4322/01044931.ctore 0523

Castro, A. A. (2006). Revisão sistemática com ou sem metanálise. In Elaboração e apresentação de comunicação científica (pp. 1-11).

Cayres, C. O. (2012). A dimensão do trabalho na inclusão social. In Saúde Mental e Economia Solidária - armazém das oficinas: um olhar para além da produção (pp. 182-190). Medita.

Ferro L. F, Pinto L. M., \& Burnagui, J. G. (2019). Economia solidária e saúde mental: reflexões e subsídios para a prática profissional. In: Cremasco MVF, Menz DM (org). Formação em políticas sobre drogas: Editora UFPR

Ferro, L. F., Cardoso, M. de M., \& Loureiro, M. B. (2015). Economia Solidária, Saúde Mental e a prática do terapeuta ocupacional: relatos de participantes de um grupo de geração de trabalho e renda. Cadernos de Terapia Ocupacional Da UFSCar, 23(1), 101-116. https://doi.org/10.4322/0104-4931.ctoao500

Ferro, L. F., Franzoloso, C. L. S., \& Burnagui, J. G. (2020). Redes de economia solidária: estratégia para captação de recursos. Revista de estudos universitários - REU, 46(2), 469-495.https://doi.org/10.22484/2177-5788.2020v46n2p469-495

Filizola, C. L. A., Teixeira, I. M. de C., Milioni, D. B., \& Pavarini, S. C. I. (2011). Saúde mental e Economia Solidária: a família na inclusão pelo trabalho. Revista Da Escola de Enfermagem Da U S P, 45(2), 418-425. https://doi.org/10.1590/S0080-62342011000200017

Freitas, M. M. (2012). As políticas públicas de Economia Solidária no Governo Federal: 2003 a 2010 [Universidade Estadual de Campinas]. http://repositorio.unicamp.br/jspui/handle/REPOSIP/285918

Gadotti, M. (2009). Economia Solidária como práxis pedagógica. Editora e Livraria Instituto Paulo Freire.

Goerck, C., \& Damascena, M. B. (2009). A implantação do programa de economia solidária em desenvolvimento por meio da SENAES no Rio Grande do Sul. 
Otra Economía - Revista Latinoamericana de Economia Social y Solidaria, 3(5), 104-124. https://doi.org/10.4013/1161

Heckert, S. M. R. (2003). Cooperativismo popular: reflexões e perspectivas. Ed. UFJF.

Kinker, F. S. (2014). Enfrentamentos e construção de projetos de trabalho para a superação da laborterapia. Cadernos de Terapia Ocupacional Da UFSCar, 22(1), 49-61. https://doi.org/10.4322/cto.2014.006

Lei Estadual n. 19784. de 20 de dezembro de 2018 (2018). Dispõe sobre a política estadual de economia solidária. Paraná. https://bit.ly/3vS4vR0

Lei Municipal n. 1.591. de 19 de agosto de 2010 (2010). Institui no município de são josé dos pinhais, a política municipal de fomento à economia solidária, cria o conselho municipal de economia solidária, o fundo municipal de economia solidária e institui o selo de economia solidária. São José dos Pinhais, PR. https://bit.ly/2R1ScNM

Lei Municipal n. 14.786. de 23 de fevereiro de 2016 (2016). Institui a política municipal de fomento à economia popular solidária e cria o conselho municipal de economia popular solidária. Curitiba, PR. https://bit.ly/3fRZT84

Lei n. 10.216. de 06 de abril de 2001 (2001). Dispõe sobre a proteção e os direitos das pessoas portadoras de transtornos mentais e redireciona o modelo assistencial em saúde mental. Brasília, DF. http://www.planalto.gov.br/ccivil_03/leis/leis_2001/110216.htm

Lei n. 9.867. de 10 de novembro de 1999 (1999). Dispõe sobre a criação e o funcionamento de Cooperativas Sociais, visando à integração social dos cidadãos, conforme especifica. Brasília, DF. https://bit.ly/3ciO1cW

Lima, I. B., Silva, J. E., \& Cruz, S. de S. (2013). Políticas públicas de Saúde Mental e Economia Solidária: construção de uma nova concepção. Rev Enferm UFPE on Line, 7, 1008-1023. https://doi.org/10.5205/reuol.3934-31164-1-SM.0703esp201324

Lussi, I. A. de O., \& Morato, G. G. (2012). O significado do trabalho para usuários de serviços de saúde mental inseridos em projetos de geração de renda vinculados ou não ao movimento da economia solidária. Cadernos de Terapia Ocupacional Da UFSCar, 20(3), 369-380. https://doi.org/10.4322/cto.2012.037

Lussi, I. A. de O., \& Pereira, M. A. O. (2011). Empresa social e Economia Solidária: perspectivas no campo da inserção laboral de portadores de transtorno mental. Revista Da Escola de Enfermagem Da USP, 45(2), 515-521. https://doi.org/10.1590/s0080-62342011000200030

Lussi, I. A. de O., \& Shiramizo, C. D. S. S. (2013). Oficina integrada de geração de trabalho e renda: estratégia para formação de empreendimento econômico solidário. Revista de Terapia Ocupacional Da Universidade de São Paulo, 24(1), 28. https://doi.org/10.11606/issn.2238-6149.v24i1p28-37

Martins, L. A. S., Oliani, F. da S., \& Riffel, C. M. (2017). Tecendo redes de solidariedade: uma aposta de fortalecimento da Economia Solidária na Região da Foz do Rio Itajaí/SC. Insular.

Ministério da Saúde. Secretaria de Atenção à Saúde. Departamento de Ações Programáticas Estratégicas. Saúde mental e economia solidária: inclusão social pelo trabalho (2005). Ministério da Saúde, Secretaria de Atenção à Saúde, Departamento de Ações Programáticas e Estratégicas. - Brasília: Editora do Ministério da Saúde. https://www.nescon.medicina.ufmg.br/biblioteca/imagem/1219.pdf

Minayo, M. C. de S., \& Guerriero, I. C. Z. (2014). Reflexividade como éthos da pesquisa qualitativa. Ciencia e Saude Coletiva, 19(4), 1103-1112. https://doi.org/10.1590/1413-81232014194.18912013

Moraes, R. C. P. de., \& Castro-Silva, C. R. de. (2016). Sentidos e processos psicossociais envolvidos na inclusão pelo trabalho na Saúde Mental. Psicologia: Ciência e Profissão, 36(3), 748-762. https://doi.org/10.1590/1982-3703002372015

Morato, G. G., \& Lussi, I. A. de O. (2015). Iniciativas de geração de trabalho e renda, economia solidária e terapia ocupacional: aproximações possíveis e construções necessárias. Cadernos de Terapia Ocupacional Da UFSCar, 23(4), 733-745. https://doi.org/10.4322/0104-4931.ctoao0737

Pedroza, A., Oliveira, F., Fortunato, M., \& Soares, P. (2012). Articulação Saúde Mental e Economia Solidária: relato de projeto de inclusão social. Revista Da Rede de Enfermagem Do Nordeste, 13(2), 454-462. https://doi.org/10.15253/revrene.v13i2.229

Pinho, K. L. R., Pinho, L. P., Lussi, I. A. de O., \& Machado, M. L. T. (2014). Relatos de experiências em inclusão social pelo trabalho na saúde. Compacta Gráfica e Editora.

Pitta, A. (2016). Reabilitação psicossocial no Brasil (4th ed.). Editora Hucitec.

Portaria n. 3.088, de 23 de dezembro de 2011 (2011). Institui a Rede de Atenção Psicossocial para pessoas com sofrimento ou transtorno mental e com necessidades decorrentes do uso de crack, álcool e outras drogas, no âmbito do Sistema Único de Saúde (SUS). Ministério da Saúde. Brasília, DF. http://bvsms.saude.gov.br/bvs/saudelegis/gm/2011/prt3088_23_12_2011_rep.html

Portaria n. 3.588, de 21 de dezembro de 2017 (2017a). Altera as Portarias de Consolidação no 3 e $\mathrm{n}^{\circ}$ 6, de 28 de setembro de 2017 , para dispor sobre a Rede de Atenção Psicossocial, e dá outras providências. Ministério da Saúde. Brasília, https://bvsms.saude.gov.br/bvs/saudelegis/gm/2017/prt3588_22_12_2017.html

Portaria de consolidação n. 3, de 28 de setembro de 2017 (2017b). Consolidação das normas sobre as redes do Sistema Único de Saúde. https://bvsms.saude.gov.br/bvs/saudelegis/gm/2017/prc0003_03_10_2017.html

Projeto de lei n. 528, de 25 de fevereiro de 2021 (2021). Dispõe sobre a organização e o funcionamento das Cooperativas e Associações Sociais; institui o Programa Nacional de Fomento às Associações e Cooperativas Sociais - PRONACOOP SOCIAL. https://www.camara.leg.br/propostas-legislativas/2270914

Relatório Final da II Conferência Nacional de Economia Solidária, de maio $2010 \quad$ (2010b). Brasília, DF. <http:/l portal.mte.gov.br/data/files/8A7C812D36A28000013731C8C25D7CEE/II_coanes_documento_final.pdf>

Relatório Final da IV Conferência Nacional de Saúde Mental-Intersetorial, 27 de junho a 1 de julho de 2010 http://conselho.saude.gov.br/biblioteca/Relatorios/relatorio_final_IVcnsmi_cns.pdf

(2010). Brasília,

DF. 
Research, Society and Development, v. 10, n. 7, e57710716924, 2021

(CC BY 4.0) | ISSN 2525-3409 | DOI: http://dx.doi.org/10.33448/rsd-v10i7.16924

Rimoli, J., \& Cayres, C. O. (2012). Saúde Mental e Economia Solidária - armazém das oficinas: um olhar para além da produção. Medita.

Rodrigues, K. L., \& Pinho, L. P. (2012). Oficinas de trabalho: limites e desafios paa inclusão social pelo trabalho na saúde mental. In Saúde Mental e Economia Solidária - armazém das oficinas: um olhar para além da produção (pp. 196-205). Medita.

Santiago, E., \& Yasui, S. (2015). Saúde Mental e Economia Solidária: cartografias do seu discurso político. Psicologia \& Sociedade, 27(3), 700-711. https://doi.org/10.1590/1807-03102015v27n3p700

Saraceno B. (2001) Libertando identidades: da reabilitação psicossocial à cidadania possível. (2ª ed.). Te Corá/Instituto Franco Basaglia.

Silva, A. P. D. da, \& Ferigato, S. H. (2017). Saúde Mental e trabalho: diálogos sobre direito, desejo e necessidade de acesso. Cadernos Brasileiros de Terapia Ocupacional, 25(4), 803-816. https://doi.org/10.4322/2526-8910.ctoao0951

Singer, P. (2002). Introdução à Economia Solidária. Editora Fundação Perseu Abramo.

Singer, P. (2005). Economia Solidária como ato pedagógico. In Economia Solidária e a educação de jovens e adultos (pp. 15-20). Inep/MEC. 